\title{
Mosquito Attraction: Crucial Role of Carbon Dioxide in Formulation of a Five-Component Blend of Human-Derived Volatiles
}

\author{
Joop J. A. van Loon ${ }^{1} \cdot$ Renate C. Smallegange ${ }^{1}$ - Gabriella Bukovinszkiné-Kiss ${ }^{1,2}$ • \\ Frans Jacobs $^{1}$ - Marjolein De Rijk ${ }^{1}$ - Wolfgang R. Mukabana ${ }^{3,4} \cdot$ Niels O. Verhulst $^{1}$ • \\ David J. Menger ${ }^{1} \cdot$ Willem Takken ${ }^{1}$
}

Received: 12 November 2014 /Revised: 28 April 2015 / Accepted: 1 May 2015 / Published online: 31 May 2015

(C) The Author(s) 2015. This article is published with open access at Springerlink.com

\begin{abstract}
Behavioral responses of the malaria mosquito Anopheles coluzzii (An. gambiae sensu stricto molecular 'M form') to an expanded blend of human-derived volatiles were assessed in a dual-port olfactometer. A previously documented attractive three-component blend consisting of $\mathrm{NH}_{3},(S)$ lactic acid, and tetradecanoic acid served as the basis for expansion. Adding $4.5 \% \mathrm{CO}_{2}$ to the basic blend significantly enhanced its attractiveness. Expansion of the blend with four human-derived $\mathrm{C} 4$-volatiles was then assessed, both with and without $\mathrm{CO}_{2}$. Only when $\mathrm{CO}_{2}$ was offered simultaneously, did addition of a specific concentration of 3-methyl-1-butanol or 3-methyl-butanoic acid significantly enhance attraction. The functional group at the terminal $\mathrm{C}$ of the 3-methyl-substituted $\mathrm{C} 4$ compounds influenced behavioral effectiveness. In the absence of $\mathrm{CO}_{2}$, addition of three concentrations of butan-1amine caused inhibition when added to the basic blend. In contrast, when $\mathrm{CO}_{2}$ was added, butan-1-amine added to the basic blend strongly enhanced attraction at all five concentrations tested, the lowest being 100,000 times diluted. The reversal of inhibition to attraction by adding $\mathrm{CO}_{2}$ is unique in the class Insecta. We subsequently augmented the three-
\end{abstract}

Joop J. A. van Loon

joop.vanloon@wur.nl

1 Laboratory of Entomology, Wageningen University, P.O. Box 16, 6700 AA Wageningen, The Netherlands

2 Laboratory of Genetics, Wageningen University, P.O. Box 309, 6700 AH Wageningen, The Netherlands

3 International Centre of Insect Physiology and Ecology, P.O. Box 30772-00100 GPO, Nairobi, Kenya

4 School of Biological Sciences, University of Nairobi, P.O. Box 30197-00100 GPO, Nairobi, Kenya component basic blend by adding both butan-1-amine and 3methyl-1-butanol and optimizing their concentrations in the presence of $\mathrm{CO}_{2}$ in order to significantly enhance the attractiveness to An. coluzzii compared to the three- and fourcomponent blends. This novel blend holds potential to enhance malaria vector control based on behavioral disruption.

Keywords Olfaction - Behavioral disruption $\cdot$ Kairomone Trapping · Carbon dioxide - Anopheles gambiae .

Butan-1-amine $\cdot 3$-methyl-1-butanol

\section{Introduction}

Mosquitoes belong to a group of blood-feeding insects that contribute to transmission of serious infectious diseases like dengue, malaria, chikungunya, and Rift Valley fever. Among these, malaria mosquitoes in the genus Anopheles are the most important species because of their high prevalence and incidence of infection with malaria parasites, Plasmodium spp. (WHO 2013). Although significant reductions in malaria have been achieved in the last decade, mainly through the Roll Back Malaria program of the World Health Organization, further progress in malaria control can be achieved by rational and novel strategies to add to the armament of existing tools (Alonso et al. 2011).

Anopheline mosquitoes feed on humans as blood hosts, enabling the transmission of Plasmodium parasites from infected to uninfected hosts. Vector-host contact is achieved through chemoreception of volatile cues emitted by the blood host (Zwiebel and Takken 2004). Host volatiles are perceived by olfactory organs located on the head of the mosquito, in particular the antennae and maxillary palps (Qiu and Van Loon 2010). In recent years, the molecular basis of olfactory 
perception of mosquitoes has been elucidated by the discovery of a suite of olfactory receptor (OR) genes that recognize volatile host cues (Carey et al. 2010; Liu et al. 2010). Binding of the host-derived volatile organic molecules to ORs trigger signal transduction in olfactory receptor neurons, which transmit electrophysiological activity to the olfactory lobe in the brain ultimately leading to a behavioral response (Qiu and Van Loon 2010). Recently, significant progress has been made in the identification of a number of these odorants, resulting in the creation of odor blends that are as attractive as a human host (Menger et al. 2014; Mukabana et al. 2012; Okumu et al. 2010). These blends have been formulated during an iterative process involving molecular, physiological, and behavioral assays on anopheline mosquitoes in vitro and in vivo (Carey et al. 2010; Carlson and Carey 2011; Qiu et al. 2011; Rinker et al. 2012; Smallegange et al. 2010, 2012).

In the present study, we re-assessed the role of carbon dioxide in attraction of the African malaria mosquito $A n$. coluzzii Coetzee \& Wilkerson sp. n. (renamed from An. gambiae sensu stricto molecular 'M-form'; Coetzee et al. 2013) to odor blends composed of C4-compounds, which have previously been reported to be attractive or inhibitory in the absence of carbon dioxide (Smallegange et al. 2012; Verhulst et al. 2011a). This finding led us to augment the three-component blend of ammonia, lactic acid, and tetradecanoic acid that we reported before as an effective kairomone blend mimicking the attraction of human subjects (Smallegange et al. 2009, 2012) with butan-1-amine and 3methyl-1-butanol, a volatile produced by microbiota on the human skin (Verhulst et al. 2009, 2011a).

\section{Methods and Materials}

Mosquitoes The female mosquitoes used for the laboratory experiments were collected from the colony of the Suakoko strain of An. coluzzii reared at Wageningen University, The Netherlands, where it has been reared on human blood from 1988 onward. Larvae were kept in tap water and fed on Tetramin ${ }^{\circledR}$ fish food (Tetrawerke, Melle, Germany). Pupae were collected daily and transferred to cubic gauze cages $(30 \times 30 \times 30 \mathrm{~cm})$ for emergence. Adult mosquitoes were kept under an $12 / 12 \mathrm{~h} \mathrm{~L} / \mathrm{D}$ photo:scotophase at $27 \pm 1{ }^{\circ} \mathrm{C}$ and $80 \pm$ $5 \%$ relative humidity $(\mathrm{RH})$, and provided with a $6 \%$ glucose solution on filter paper ad libitum.

Tested Compounds We tested four C4-compounds functionalized at the 1-and/or 3-positions: 3-methylbutanoic acid (syn. isovaleric acid; Sigma-Aldrich; $99 \%$ pure), 3-methyl-1butanol (Fluka, 99.8\%), 3-methylbutanal (Fluka, $98 \%$ ), and butan-1-amine (Sigma-Aldrich, $99 \%$ ). The first three are produced by human skin-associated bacteria that use fatty acids produced by eccrine sweat glands as substrates (James et al.
2004; Verhulst et al. 2011a,b). The amine occurs in human effluvia and feces (Ellin et al. 1974; Smith and Macfarlane 1996). Each compound was added individually to a threecomponent basic blend, consisting of ammonia, $(S)$-lactic acid, and tetradecanoic acid (Table 1; Smallegange et al. 2005), to test their effect on the degree of attractiveness of the reference blend (Smallegange et al. 2009; Verhulst et al. 2010, 2011a). The resulting blends were tested either as such or augmented with $\mathrm{CO}_{2}$ since this compound has been found essential to evoke a behavioral response in (semi-)field settings (Njiru et al. 2006; Schmied et al. 2008). To guarantee a constant emission rate of the individual compounds within and between experiments, all compounds (except $\mathrm{CO}_{2}$ ) were dispensed individually from low density polyethylene (LDPE) sachets (Audion Elektro, The Netherlands; Smallegange et al. 2012; Torr et al. 1997) with a sealed area of $25 \times 25 \mathrm{~mm}$, and variable sheet thickness (thickness stated in Table 1 for the three components of the basic blend; $0.20 \mathrm{~mm}$ was used for the C4-compounds). The sachets were suspended from metal hooks that were placed inside the trapping devices in the olfactometer (Smallegange et al. 2012; Verhulst et al. 2010)

Olfactometer Experiments In the laboratory, a three-layer olfactometer was used, consisting of three polycarbonate flight chambers (each $1.50 \times 0.50 \times 0.50 \mathrm{~m}$ ) on top of each other, allowing us to run three experiments simultaneously (Smallegange et al. 2012; Verhulst et al. 2010). Mosquito rearing, preparation and the performance of the olfactometer experiments, as well as cleaning of the olfactometer parts, were done as described in Smallegange et al. (2012). The air flowing into the flight chambers was maintained at a relative humidity above $70 \%$ and had an average temperature of 26.6 $\pm 1.1^{\circ} \mathrm{C}$. Data loggers (type MSR1455, MSR Electronics $\mathrm{GmbH}$, Switzerland) mounted inside the flight chambers measured an average temperature and relative humidity of $26.7 \pm$ $0.8{ }^{\circ} \mathrm{C}$ and $62.7 \pm 5.9 \%$, respectively. Each blend was tested six to eight times, on different days. The sequence in which different concentrations of a compound were tested was randomized on the same day and between days, and between the three flight chambers. Controls and treatments were alternated between right and left ports in different replicates to rule out any positional effects. Experiments with clean air only in either port were done to confirm the symmetry of the trapping systems (data not shown). Air containing $4.5 \% \mathrm{CO}_{2}$ was released at $250 \mathrm{ml} / \mathrm{s}$ from glass pipette tips, placed inside the flight chamber at $5 \mathrm{~cm}$ in front of each olfactometer port (Spitzen et al. 2008).

Optimization of an Attractive Blend Containing Butan-1amine and 3-Methyl-1-butanol Additional tests were designed to determine the effect of adding butan-1-amine and 3-methyl-1-butanol, at a range of concentrations in paraffin 
Table 1 Composition of the attractive basic blend used in the olfactometer experiments

\begin{tabular}{|c|c|c|c|}
\hline Compound & $\begin{array}{l}\text { Concentration } \\
(\% \text { in } \mathrm{w} / \mathrm{w})\end{array}$ & $\begin{array}{l}\text { LDPE sheet } \\
\text { thickness }(\mathrm{mm})\end{array}$ & Solvent \\
\hline Ammonia & 25 & 0.03 & Distilled water \\
\hline$(S)$-Lactic acid & $88-92$ & 0.05 & Distilled water \\
\hline Tetradecanoic acid & $>99$ & 0.03 & (Solid) \\
\hline
\end{tabular}

oil, to the basic blend in the presence of $\mathrm{CO}_{2}$. Butan-1-amine was added to blends containing various dilutions of 3-methyl1-butanol to assess whether certain combinations would be more attractive than blends without butan-1-amine.

\section{Statistical Analysis}

For each two-choice olfactometer experiment a $\chi^{2}$-test was used to test whether the distribution of the total number of mosquitoes caught in the treatment or control trapping device over all replicates differed from a 50:50 distribution at $\alpha=$ 0.05 .

\section{Results}

Effect of C4-Compounds on Attractiveness of the ThreeCompound Basic Blend $\left(\mathrm{NH}_{3}+\mathrm{LA}+\mathrm{C} 14\right)$ with or without $\mathrm{CO}_{2}$ Adding 3-methyl-1-butanol (at $0.01 \%$ ) or 3methylbutanal (at $1 \%$ ) resulted in significantly enhanced attraction in the absence of $\mathrm{CO}_{2}$, whereas 3-methylbutanoic acid was ineffective at the three concentrations tested (Table 2; data on four-component blends without $\mathrm{CO}_{2}$ taken from Verhulst et al. (2011a)). In contrast, adding butan-1-amine to the basic blend in the absence of $\mathrm{CO}_{2}$ inhibited the trap entry response at all three concentrations tested (Fig. 1; data on fourcomponent blends without $\mathrm{CO}_{2}$ taken from Smallegange et al. (2012)).

A significant increase in attractiveness compared to that exerted by the basic blend alone was observed when $\mathrm{CO}_{2}$ was added (Fig. 1). In the presence of $\mathrm{CO}_{2}$, adding 3methyl-1-butanol or 3-methylbutanoic acid at $0.1 \%$ significantly increased the attractiveness of the basic blend $(P=$ 0.007 and $P=0.02$, respectively). A reverse effect was found for 3-methylbutanal, the addition of which significantly inhibited the response to the basic blend in the presence of $\mathrm{CO}_{2}$ at $0.1 \%$ (Table 2). Remarkably, adding butan-1-amine in the presence of $\mathrm{CO}_{2}$ completely reversed the inhibitory effect of this compound to strong attraction at the three concentrations tested. Significantly higher attractiveness was preserved after diluting the lowest of the three concentrations of butan-1amine by a factor of 10 and 100 (Fig. 1).
The overall response rate (expressed as the percentage of all released mosquitoes entering either trap) ranged from 17 to $42 \%$ in the absence of $\mathrm{CO}_{2}$, and from 31 to $68 \%$ in the presence of $\mathrm{CO}_{2}$. The highest values were found for butan1-amine (59-67 \%) and 3-methylbutanoic acid (47-68 \%).

Formulation of a Five-Component Attractive Blend Containing Butan-1-amine and 3-Methyl-1-butanol In the presence of carbon dioxide, particular concentrations of 3methyl-1-butanol, 3-methylbutanoic acid, and all five concentrations of butan-1-amine increased the attractiveness of the basic blend. Due to the malodor associated with 3methylbutanoic acid, we discarded it for further tests (Okumu et al. 2010). We subsequently tested which concentrations of 3-methyl-1-butanol and butan-1-amine and their combinations significantly augmented the attractiveness of the basic blend in the presence of $\mathrm{CO}_{2}$, with the aim to find the lowest active concentrations (Fig. 2). When the basic blend was prepared with $0.01 \% 3$-methyl-1-butanol, the addition of $0.01,0.004$, or $0.001 \%$ butan-1-amine resulted in higher trap catches $\left(\chi^{2}\right.$-test, $\left.P \leq 0.001\right)$. When $0.001 \% 3$ methyl-1-butanol was added to the basic blend, the addition of 0.01 or $0.004 \%$ butan- 1 -amine resulted in a higher number of trapped mosquitoes $\left(\chi^{2}\right.$-test, $\left.P<0.001\right)$. Other combinations did not lead to significant preferences for either one of the blends.

\section{Discussion}

Carbon Dioxide: An Essential Component of Host-derived Kairomone Blends In a previous study we tested the effect of butan-1-amine on the behavioral response of An. coluzzii. We found that in the absence of $\mathrm{CO}_{2}$ significantly more mosquitoes were caught in the port with the three-component basic blend than with this blend to which butan-1-amine at concentrations of $0.01,0.1$, and $1.0 \%$ had been added (Smallegange et al. 2012), suggesting an inhibitory effect caused by butan-1amine. In the laboratory assays that we have employed thus far, $\mathrm{CO}_{2}$ was not needed to demonstrate kairomonal effects of volatile compounds with this anopheline species (Smallegange et al. 2005, 2009, 2012), and data presented here corroborate this. However, in order to mimic the standard trapping method in (semi-)field test conditions more closely (Mukabana et al. 2012), in the present study, $\mathrm{CO}_{2}$ was added to the basic blend in the laboratory olfactometer bioassays. This resulted in a significantly enhanced attractiveness and overall increase of the response rate. Unexpectedly, butan-1amine, added to the basic blend $+\mathrm{CO}_{2}$, evoked strong attraction of An. coluzzii. Indeed, progressive dilutions of butan-1amine to 1:100,000 elicited a highly significant preference, with trap entry responses ranging between 65.2 and $66.5 \%$ (Fig. 1). To the best of our knowledge, the remarkable reversal 
Table 2 Response of Anopheles coluzzii to three bacterial C4compounds tested in a dual-choice olfactometer in three concentrations in low density polyethylene (LDPE) sachets in the presence of the threecomponent basic blend consisting of $\mathrm{NH}_{3},(S)$-lactic acid, and tetradecanoic acid, with $(+)$ or without $(-)$ carbon dioxide. Control $=$ basic blend $(-)$ or basic blend + carbon dioxide $(+)$. Data for four- component blends without carbon dioxide were taken from Verhulst et al. (2011a) and reproduced here for direct comparison. Values for control and treatment refer to the numbers of mosquitoes caught out of the total number that left the release cage $(N)$ over six replicated tests $\left(N_{\max }=180\right)$. Percentages refer to overall response. $P$-values are based on $\chi^{2}$-tests

\begin{tabular}{|c|c|c|c|c|c|c|c|}
\hline \multirow{2}{*}{$\begin{array}{l}\text { Compound added } \\
\text { to basic blend }\end{array}$} & \multirow{2}{*}{$\begin{array}{l}4.5 \% \\
\mathrm{CO}_{2}\end{array}$} & \multicolumn{2}{|l|}{$0.01 \%$} & \multicolumn{2}{|l|}{$0.1 \%$} & \multicolumn{2}{|l|}{$1 \%$} \\
\hline & & Control & Treatment & Control & Treatment & Control & Treatment \\
\hline \multirow[t]{4}{*}{ 3-methyl-1-butanol } & - & 25 & 41 & 28 & 20 & 31 & 29 \\
\hline & & \multicolumn{2}{|c|}{$\begin{array}{l}P=0.048 \\
(N=157,42 \%)\end{array}$} & \multicolumn{2}{|c|}{$\begin{array}{l}P=0.25 \\
(N=158,30 \%)\end{array}$} & \multicolumn{2}{|c|}{$\begin{array}{l}P=0.80 \\
(N=163,37 \%)\end{array}$} \\
\hline & + & 37 & 43 & 25 & 48 & 26 & 27 \\
\hline & & \multicolumn{2}{|c|}{$\begin{array}{l}P=0.50 \\
(N=174,46 \%)\end{array}$} & \multicolumn{2}{|c|}{$\begin{array}{l}P=0.007 \\
(N=175,42 \%)\end{array}$} & \multicolumn{2}{|c|}{$\begin{array}{l}P=0.89 \\
(N=171,31 \%)\end{array}$} \\
\hline \multirow[t]{4}{*}{ 3-methylbutanal } & - & 16 & 16 & 21 & 24 & 18 & 34 \\
\hline & & \multicolumn{2}{|c|}{$\begin{array}{l}P=1.0 \\
(N=172,19 \%)\end{array}$} & \multicolumn{2}{|c|}{$\begin{array}{l}P=0.65 \\
(N=158,28 \%)\end{array}$} & \multicolumn{2}{|c|}{$\begin{array}{l}P=0.03 \\
(N=170,31 \%)\end{array}$} \\
\hline & + & 49 & 46 & 63 & 34 & 42 & 56 \\
\hline & & \multicolumn{2}{|c|}{$\begin{array}{l}P=0.76 \\
(N=169,56 \%)\end{array}$} & \multicolumn{2}{|c|}{$\begin{array}{l}P=0.003 \\
(N=176,55 \%)\end{array}$} & \multicolumn{2}{|c|}{$\begin{array}{l}P=0.16 \\
(N=178,55 \%)\end{array}$} \\
\hline \multirow{4}{*}{$\begin{array}{l}\text { 3-methylbutanoic } \\
\text { acid }\end{array}$} & - & 18 & 30 & 24 & 33 & 25 & 22 \\
\hline & & \multicolumn{2}{|c|}{$\begin{array}{l}P=0.08 \\
(N=161,30 \%)\end{array}$} & \multicolumn{2}{|c|}{$\begin{array}{l}P=0.23 \\
(N=161,35 \%)\end{array}$} & \multicolumn{2}{|c|}{$\begin{array}{l}P=0.66 \\
(N=163,29 \%)\end{array}$} \\
\hline & + & 56 & 52 & 37 & 61 & 47 & 34 \\
\hline & & \multicolumn{2}{|c|}{$\begin{array}{l}P=0.23 \\
(N=171,68 \%)\end{array}$} & \multicolumn{2}{|c|}{$\begin{array}{l}P=0.02 \\
(N=175,56 \%)\end{array}$} & \multicolumn{2}{|c|}{$\begin{array}{l}P=0.15 \\
(N=174,47 \%)\end{array}$} \\
\hline
\end{tabular}

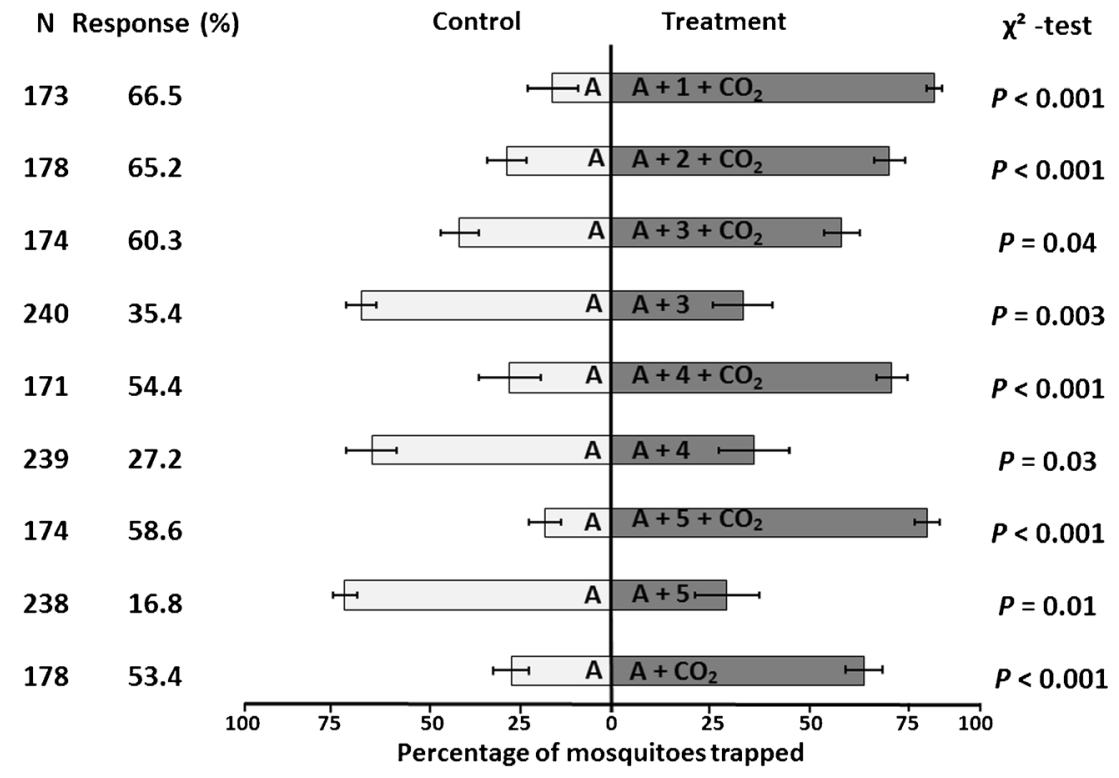

Fig. 1 Reversal of repellence to attraction of Anopheles coluzzii by butan-1-amine depending on addition of carbon dioxide. Mean percentages of released mosquitoes that were trapped with the respective odor blends. Error bars represent SEM. $N$ is the total number of mosquitoes that were introduced in the olfactometer, six to eight groups of 30 females minus the ones that did not leave the release cage. The six to eight bioassays were performed on at least three test days. The response is the percentage that was trapped by the end of the 15-min experiment. The numbers placed inside the bars indicate the compound(s) and concentrations that were added to the basic blend consisting of $\mathrm{NH}_{3}$, (S)-lactic acid, and tetradecanoic acid. Mean percentages of mosquitoes that were trapped when exposed to the basic blend (A) augmented with butan-1-amine in five concentrations, with or without carbon dioxide. $P$ values are based on $\chi^{2}$-tests. Data for four-component blend without carbon dioxide were taken from Smallegange et al. (2012) and reproduced here for direct comparison. $\mathrm{A}=$ basic blend; 1 : $0.001 \%$ butan-1-amine; 2: $0.004 \%$; 3: $0.01 \%$ butan-1-amine; 4: $0.1 \%$ butan-1amine; 5: $1.0 \%$ butan-1-amine 


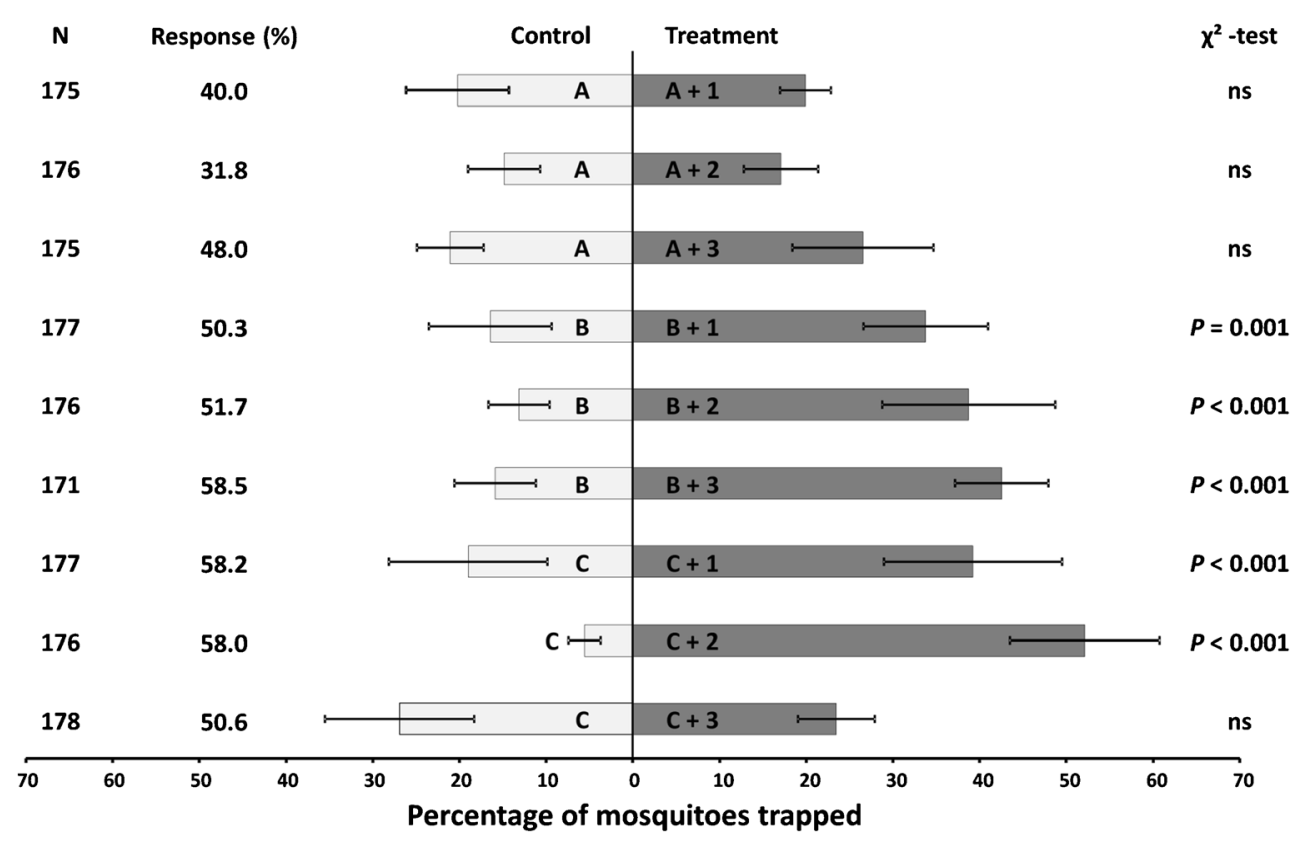

Fig. 2 Olfactory bioassays testing different blend ratios of 3-methyl-1butanol and butan-1-amine. Mean percentages of released mosquitoes that were trapped with the respective odor blends. Error bars represent SEM. $N$ is the total number of mosquitoes that were introduced in the olfactometer, six groups of 30 females minus the ones that did not leave the release cage. The six bioassays were performed on at least three test days. The response is the percentage that was trapped by the end of the 15-min experiment. $P$-values are based on $\chi^{2}$-tests. The letters and numbers placed inside the bars indicate the compound(s) and concentrations that were added to the basic blend consisting of $\mathrm{NH}_{3}$, $(S)$-lactic acid, and tetradecanoic acid and $4.5 \% \mathrm{CO}_{2}: \mathrm{A}=0.1 \% 3-$ methyl-1-butanol; $\mathrm{B}=0.01 \% 3$-methyl-1-butanol; $\mathrm{C}=0.001 \% 3$ methyl-1-butanol; $1=0.01 \%$ butan-1-amine; $2=0.004 \%$ butan-1amine; $3=0.001 \%$ butan-1-amine of the behavioral effect of butan-1-amine that depends on the presence of $\mathrm{CO}_{2}$ is unique in insect chemical ecology and highlights a crucial role in the kairomone blend. Geier and Boeckh (1999) reported that both $\mathrm{CO}_{2}$ and $(S)$-lactic acid were attractive on their own to Ae. aegypti (L.), and that their combination exerted a more than additive attraction. More generally, both activating and attractant roles have been ascribed to $\mathrm{CO}_{2}$ in the host-seeking behavior of mosquitoes and other hematophagous insects (Gillies 1980; McMeniman et al. 2014; Mboera and Takken 1997). Small fluctuations in carbon dioxide concentrations recently have been demonstrated to increase the frequency of landing behavior on human-odor treated gauze (Webster et al. 2015).

The ionotropic (IR) family of olfactory receptors now has been identified (Benton et al. 2009; Guo et al. 2014), expanding the range of olfactory receptors to include those binding more polar molecules, such as butan-1-amine and 3methylbutanoic acid. Aliphatic carboxylic acids, many of which are not binding to ORs, appear to be agonists of IRs in Drosophila melanogaster (Abuin et al. 2011). We previously have shown the importance of carboxylic acids in the behavior of anopheline mosquitoes (Smallegange et al. 2005, 2009; Okumu et al. 2010). These compounds are not among the agonists of the AgOR family of olfactory receptors (Carey et al. 2010), but are ligands of the AgIR family (Liu et al. 2010; Rinker et al. 2012) as well as to gustatory receptors (Kwon et al. 2006). Several carboxylic acids, amines and ammonia evoke a response in IRs of D. melanogaster (Abuin et al. 2011; Min et al. 2013). By contrast, 3-methyl1-butanol, a compound that activates eight AgOR receptors (Carey et al. 2010), evokes a strong behavioral response in $A n$. gambiae s.s. 'S form' (Carey et al. 2010; Mukabana et al. 2012; Verhulst et al. 2011a). The effect of the three 3methyl-substituted $\mathrm{C} 4$ compounds with either an aldehyde-, alcohol-, or carboxylic acid-group at the terminal $\mathrm{C}$ differs qualitatively, pointing to strict structural requirements for activity.

Electrophysiological studies on An. coluzzii have reported responses to ammonia, butan-1-amine, lactic acid, and 3methylbutanoic acid in olfactory receptor neurons in antennal grooved peg sensilla (Qiu et al. 2006). However, responses to 3-methyl-1-butanol and 3-methylbutanal have been detected in sensilla trichodea of response type TE1 and in capitate peg neurons (Qiu et al. 2006; Suer 2011). Neurons responding to $\mathrm{CO}_{2}$ reside in capitate peg sensilla on the maxillary palp in $\mathrm{An}$. gambiae sensu stricto 'S form' (Lu et al. 2007). Recently, McMeniman et al. (2014) demonstrated the significance of the $\mathrm{CO}_{2}$ receptor on the maxillary palp of the mosquito Aedes aegypti. RNAi-mediated silencing of this receptor showed that mosquitoes could no longer recognize their human host from a distance. ORNs in sensilla trichodea and grooved pegs project to different glomerular areas of the antennal lobe, the first integration center in the deutocerebrum of the brain (Anton et al. 2003; Anton and Rospars 2004). 
Carbon dioxide sensitive neurons contained in sensilla on the maxillary palp also project to the antennal lobe, but to a distinctly different area (Anton et al. 2003). We note that olfactory receptors of all three known classes, i.e., ORs, IRs, and GRs, are involved in the olfactory perception of $\mathrm{CO}_{2}$ and the five-component blend presented here.

\section{Formulation of a Five-Component Odor Blend That} Exhibits Increased Attractiveness Our results demonstrate that the synergistic three-component blend of ammonia, (S)-lactic acid, and tetradecanoic acid that we developed previously (Smallegange et al. 2005, 2009, 2012) can be made significantly more attractive by addition of two other compounds, butan-1-amine, increasing attractiveness synergistically when $\mathrm{CO}_{2}$ is added, and 3-methyl-1-butanol. Mweresa (2014) validated the results on the five-component blend we report here based on olfactometer assays augmented with $\mathrm{CO}_{2}$, under semi-field and field conditions in Kenya. Although Mweresa (2014) used nylon strips instead of LDPE material as odor-dispensing material, the data suggest that in both cases it was the combined effect of the fivecomponent blend $+\mathrm{CO}_{2}$ that induced the observed attraction response in An. gambiae sensu lato.

The strong and consistent responses of An. gambiae sensu lato to the five-component blend augmented with $\mathrm{CO}_{2}$ under field conditions suggests that the blend contains essential compounds in specific ratios, which these mosquitoes use for recognition of human hosts. Of these five compounds, $(S)$-lactic acid is the only compound that is unique to humans (Dekker et al. 2002), although we showed previously that $(S)$-lactic acid on its own is a poor attractant (Smallegange et al. 2005). Williams et al. (2006) reported similar findings for Ae aegypti, which was attracted only to a blend of odorants in specific ratios. For the latter species, hexanoic acid appears a crucial compound (Bosch et al. 2000), whereas in $A n$. coluzzii, it is tetradecanoic acid (Smallegange et al. 2005, 2009).

In Summary, we revealed a crucial role of $\mathrm{CO}_{2}$ in formulating a five-component blend that is significantly more attractive than a three-component blend. The five-component blend is characterized by particular ratios of the components. This blend holds promise for behavioral disruption of host-seeking mosquitoes (Menger et al. 2014; Mukabana et al. 2012; Okumu et al. 2010). It can be utilized to overcome the need to use human volunteers for the surveillance of malaria mosquitoes to monitor disease epidemiology, for mass trapping of malaria vectors, and contribute to reduced likelihood of mosquito biting.

Acknowledgments We thank Frans van Aggelen, André Gidding, and Léon Westerd, Wageningen University, for having reared the mosquitoes for the olfactometer experiments. The advice provided by Larry Zwiebel, Vanderbilt University, and John Carlson, Yale University, is appreciated.
This study was funded by a grant from the Foundation for the National Institutes of Health (FNIH) through the Grand Challenges in Global Health Initiative (GCGH\#121).

Open Access This article is distributed under the terms of the Creative Commons Attribution 4.0 International License (http:// creativecommons.org/licenses/by/4.0/), which permits unrestricted use, distribution, and reproduction in any medium, provided you give appropriate credit to the original author(s) and the source, provide a link to the Creative Commons license, and indicate if changes were made.

\section{References}

Abuin L, Bargeton B, Ulbrich MH, Isacoff EY, Kellenberger S, Benton R (2011) Functional architecture of olfactory ionotropic glutamate receptors. Neuron 69:44-60

Alonso PL, Brown G, Arevalo-Herrera M, Binka F, Chitnis C, Collins F, Doumbo OK, Greenwood B, Hall BF, Levine MM et al (2011) A research agenda to underpin malaria eradication. PLoS Med 8, e1000406

Anton S, Rospars JP (2004) Quantitative analysis of olfactory receptor neuron projections in the antennal lobe of the malaria mosquito, Anopheles gambiae. J Comp Neurol 475:315-326

Anton S, Van Loon JJA, Meijerink J, Smid HM, Takken W, Rospars JP (2003) Central projections of olfactory receptor neurons from single antennal and palpal sensilla in mosquitoes. Arthropod Struct Dev 32:319-327

Benton R, Vannice KS, Gomez-Diaz C, Vosshall LB (2009) Variant ionotropic glutamate receptors as chemosensory receptors in Drosophila. Cell 136:149-162

Bosch O, Geier M, Boeckh J (2000) Contribution of fatty acids to olfactory host finding of female Aedes aegypti. Chem Senses 25:323-330

Carey AF, Wang G, Su CY, Zwiebel LJ, Carlson JR (2010) Odorant reception in the malaria mosquito Anopheles gambiae. Nature 464: 66-71

Carlson JR, Carey AF (2011) Scent of a human: decoding how a mosquito sniffs out human targets could lead to better traps and repellents that cut malaria's spread. Sci American 305:76-79

Coetzee M, Hunt RH, Wilkerson R, Della Torre A, Coulibaly MB, Besansky NJ (2013) Anopheles coluzzii and Anopheles amharicus, new members of the Anopheles gambiae complex. Zootaxa 3619: 246-274

Dekker T, Steib B, Cardé RT, Geier M (2002) L-lactic acid: a humansignifying host cue for the anthropophilic mosquito Anopheles gambiae. Med Vet Entomol 16:91-98

Ellin RI, Farrand RL, Oberst FW, Crouse CL, Billups NB, Koon WS, Musselman NP, Sidell FR (1974) An apparatus for the detection and quantitation of volatile human effluents. J Chromatogr A 100:137152

Geier M, Boeckh J (1999) A new Y-tube olfactometer for mosquitoes to measure the attractiveness of host odours. Entomol Exp Appl 92:9 19

Gillies MT (1980) The role of carbon dioxide in host-finding by mosquitoes (Diptera: Culicidae): a review. Bull Entomol Res 70:525-532

Guo M, Krieger J, Grosse-Wilde E, Missbach C, Zhang L, Breer H (2014) Variant ionotropic receptors are expressed in olfactory sensory neurons of coeloconic sensilla on the antenna of the Desert Locust (Schistocerca gregaria). Int J Biol Sci 10:1-14

James GA, Casey J, Hyliands D, Mycock G (2004) Fatty acid metabolism by cutaneous bacteria and its role in axillary malodour. World $\mathrm{J}$ Microbiol Biotech 20:787-793 
Kwon HW, Lu T, Rutzler M, Zwiebel LJ (2006) Olfactory responses in a gustatory organ of the malaria vector mosquito Anopheles gambiae. Proc Natl Acad Sci U S A 103:13526-13531

Liu C, Pitts RJ, Bohbot JD, Jones PL, Wang GR, Zwiebel LJ (2010) Distinct olfactory signaling mechanisms in the malaria vector mosquito Anopheles gambiae. PLoS Biol 8, e1000467

Lu T, Qiu YT, Wang G, Kwon J, Rutzler M, Kwon HW, Pitts RJ, Van Loon JJA, Takken W, Carlson JR, Zwiebel LJ (2007) Odor coding in the maxillary palp of the malaria vector mosquito Anopheles gambiae. Curr Biol 17:1533-1544

Mboera LEG, Takken W (1997) Carbon dioxide chemotropism in mosquitoes (Diptera: Culicidae) and its potential in vector surveillance and management programmes. Med Vet Entomol 85:355-368

McMeniman CJ, Corfas RA, Matthews BJ, Ritchie SA, Vosshall LB (2014) Multimodal integration of carbon dioxide and other sensory cues drives mosquito attraction to humans. Cell 156:1060-1071

Menger DJ, Van Loon JJA, Takken W (2014) Assessing the efficacy of candidate mosquito repellents against the background of an attractive source that mimics a human host. Med Vet Entomol doi:. doi:10. 1111/mve.12061

Min SH, Ai MR, Shin SA, Suh GSB (2013) Dedicated olfactory neurons mediating attraction behavior to ammonia and amines in Drosophila. Proc Natl Acad Sci U S A 110:E1321-E1329

Mukabana WR, Mweresa CK, Otieno B, Omusula P, Smallegange RC, Van Loon JJA, Takken W (2012) A novel synthetic odorant blend for trapping of malaria and other African mosquitoes. J Chem Ecol $38: 235-244$

Mweresa C (2014) Odour-based strategies for surveillance and behavioural disruption of host-seeking malaria and other mosquitoes. $\mathrm{PhD}$ thesis, Wageningen University. $277 \mathrm{pp}$

Njiru BN, Mukabana WR, Takken W, Knols BG (2006) Trapping of the malaria vector Anopheles gambiae with odour-baited MM-X traps in semi-field conditions in western Kenya. Malar J 5:39

Okumu FO, Killeen GF, Ogoma S, Biswaro L, Smallegange RC, Mbeyela E, Titus E, Munk C, Ngonyani H, Takken W et al (2010) Development and field evaluation of a synthetic mosquito lure that is more attractive than humans. PLoS One 5, e8951

Qiu YT, Van Loon JJA (2010) Olfactory physiology of blood-feeding vector mosquitoes. In: Takken W, Knols BGJ (eds) Olfaction in vector-host interactions. Wageningen Academic Publishers, Wageningen, pp 39-61

Qiu YT, Van Loon JJA, Takken W, Meijerink J, Smid HM (2006) Olfactory coding in antennal neurons of the malaria mosquito, Anopheles gambiae. Chem Senses 31:845-863

Qiu YT, Smallegange RC, Van Loon JJA, Takken W (2011) Behavioural responses of Anopheles gambiae sensu stricto to components of human breath, sweat and urine depend on mixture composition and concentration. Med Vet Entomol 25:247-255

Rinker DC, Jones PL, Pitts RJ, Rutzler M, Camp G, Sun LJ, Xu PX, Dorset DC, Weaver D, Zwiebel LJ (2012) Novel high-throughput screens of Anopheles gambiae odorant receptors reveal candidate behaviour-modifying chemicals for mosquitoes. Physiol Entomol 37:33-41

Schmied WH, Takken W, Killeen GF, Knols BG, Smallegange RC (2008) Evaluation of two counterflow traps for testing behaviourmediating compounds for the malaria vector Anopheles gambiae s.s. under semi-field conditions in Tanzania. Malar J 7:230
Smallegange RC, Qiu YT, Van Loon JJA, Takken W (2005) Synergism between ammonia, lactic acid and carboxylic acids as kairomones in the host-seeking behaviour of the malaria mosquito Anopheles gambiae sensu stricto (Diptera: Culicidae). Chem Senses 30:145152

Smallegange RC, Qiu YT, Bukovinszkine-Kiss G, Van Loon JJA, Takken W (2009) The effect of aliphatic carboxylic acids on olfaction-based host-seeking of the malaria mosquito Anopheles gambiae sensu stricto. J Chem Ecol 35:933-943

Smallegange RC, Knols BGJ, Takken W (2010) Effectiveness of synthetic versus natural human volatiles as attractants for Anopheles gambiae (Diptera: Culicidae) sensu stricto. J Med Entomol 47: 338-344

Smallegange RC, Bukovinszkine-Kiss G, Otieno B, Mbadi PA, Takken W, Mukabana WR, Van Loon JJA (2012) Identification of candidate volatiles that affect the behavioural response of the malaria mosquito Anopheles gambiae sensu stricto to an active kairomone blend: laboratory and semi-field assays. Physiol Entomol 37:60-71

Smith EA, Macfarlane GT (1996) Studies on amine production in the human colon: enumeration of amine forming bacteria and physiological effects of carbohydrate and $\mathrm{pH}$. Anaerobe 2:285-297

Spitzen J, Smallegange RC, Takken W (2008) Effect of human odours and positioning of $\mathrm{CO}_{2}$ release point on trap catches of the malaria mosquito Anopheles gambiae sensu stricto in an olfactometer. Physiol Entomol 33:116-122

Suer RA (2011) Unravelling the malaria mosquito's sense of smell: neural and behavioural responses to human-derived compounds. $\mathrm{PhD}$ thesis, Wageningen University. $204 \mathrm{pp}$

Torr SJ, Hall DR, Phelps RJ, Vale GA (1997) Methods for dispensing odour attractants for tsetse flies (Diptera: Glossinidae). Bull Ent Res 87:299-311

Verhulst N, Beijleveld H, Knols B, Takken W, Schraa G, Bouwmeester H, Smallegange RC (2009) Cultured skin microbiota attracts malaria mosquitoes. Malar J 8:302

Verhulst NO, Andriessen R, Groenhagen U, Bukovinszkiné Kiss G, Schulz S, Takken W, Van Loon JJA, Schraa G, Smallegange RC (2010) Differential attraction of malaria mosquitoes to volatile blends produced by human skin bacteria. PLoS One 5, e15829

Verhulst NO, Mbadi PA, Bukovinszkiné-Kiss G, Mukabana WR, Van Loon JJA, Takken W, And Smallegange RC (2011a) Improvement of a synthetic lure for Anopheles gambiae using compounds produced by human skin microbiota. Malar J 10:28

Verhulst NO, Mukabana WR, Takken W, Smallegange RC (2011b) Human skin microbiota and their volatiles as odour baits for the malaria mosquito Anopheles gambiae s.s. Entomol Exp Appl 139: $170-179$

Webster B, Lacey ES, Cardé RT (2015) Waiting with bated breath: opportunistic orientation to human odor in the malaria mosquito, Anopheles gambiae, is modulated by minute changes in carbon dioxide concentration. J Chem Ecol 49:55-66

WHO (2013) World Malaria report 2013. Geneva, Switzerland: World Health Organization. 253 pp

Williams CR, Bergbauer R, Geier M, Kline DL, Bernier UR, Russell RC, Ritchie SA (2006) Laboratory and field assessment of some kairomone blends for host-seeking Aedes aegypti. J Am Mosq Control Assoc 22:641-647

Zwiebel LJ, Takken W (2004) Olfactory regulation of mosquito-host interactions. Insect Biochem Mol Biol 34:645-652 